\title{
Depressive symptoms and healthcare utilization in patients with noncardiac chest pain compared to patients with ischemic heart disease
}

Ghassan Mourad, Tiny Jaarsma, Claes Hallert and Anna Strömberg

\section{Linköping University Post Print}

N.B.: When citing this work, cite the original article.

Original Publication:

Ghassan Mourad, Tiny Jaarsma, Claes Hallert and Anna Strömberg, Depressive symptoms and healthcare utilization in patients with noncardiac chest pain compared to patients with ischemic heart disease, 2012, Heart \&amp; Lung, (41), 5, 446-455.

http://dx.doi.org/10.1016/j.hrtlng.2012.04.002

Copyright: Elsevier

http://www.elsevier.com/

Postprint available at: Linköping University Electronic Press

http://urn.kb.se/resolve?urn=urn:nbn:se:liu:diva-78856 
Depressive symptoms and health-care utilization in patients with non-cardiac chest pain compared to patients with ischemic heart disease

Ghassan Mourad MSc, $\mathrm{RN}^{1}$, Tiny Jaarsma, $\mathrm{PhD}, \mathrm{RN}^{1}$, Claes Hallert, $\mathrm{PhD}, \mathrm{MD}^{1,2} \&$ Anna

Strömberg, PhD, $\mathrm{RN}^{3}$

(1) Department of Social and Welfare Studies, Faculty of Health Sciences, Linköping University, Norrköping, Sweden.

(2) Department of Internal Medicine Vrinnevi hospital, Norrköping, Sweden

(3) Division of Nursing Science, Department of Medicine and Health Sciences, Faculty of Health Sciences, Linköping University, Department of Cardiology UHL, County Council of Östergötland, Linköping, Sweden

Corresponding author: Ghassan Mourad

Address: Linköpings universitet, Kungsgatan 40 S-601 74 Norrköping

Telephone: +4611363514

Fax: +4611 125448

E-mail: ghassan.mourad@liu.se

Word count (abstract and references excluded): 3612 


\begin{abstract}
Objectives: To compare depressive symptoms and health-care utilization in patients admitted for non-cardiac chest pain, acute myocardial infarction and angina pectoris post-hospitalization and at one-year follow-up. Methods: 131 patients with non-cardiac chest pain, 66 with acute myocardial infarction and 70 with angina pectoris completed a 3 depression screening questionnaire and the Montgomery Åsberg Depression Rating Scale. Health-care utilization data were collected from a population-based diagnose-related database. Results: More than $25 \%$ had depressive symptoms, regardless of diagnosis. At follow-up, 9\%had recovered, $19 \%$ were still experiencing depressive symptoms and $13 \%$ had developed depressive symptoms. Non-cardiac chest pain patients had similar primary care contacts, but fewer hospital admissions, than acute myocardial infarction patients. Patients with angina pectoris and depressive symptoms utilized most health-care services. Conclusions: Depressive symptoms were common. Patients with noncardiac chest pain used as much primary care as acute myocardial infarction patients. Interventions should focus on identifying and treating depressive symptoms.
\end{abstract}

Key words: Non-cardiac chest pain, depressive symptoms, health-care utilization, primary care, hospital care. 


\section{Abbreviations list}

AMI: Acute Myocardial Infarction

AP: Angina Pectoris

IHD: Ischemic Heart Disease

MADRS: Montgomery Åsberg Depression Rating Scale

NCCP: Non-Cardiac Chest Pain

SQ-3: Screening Questions-3 


\section{Introduction}

Acute chest pain is a symptom indicating a possible serious condition that requires urgent medical attention for rapid identification and optimal treatment of patients with acute coronary syndrome. ${ }^{1,2}$ Chest pain is the underlying reason for approximately $1 \%$ of all primary care consultations $^{3,4}$ and 2-5\% of all emergency room presentations in Europe as well as the US. ${ }^{5,6}$ Chest pain does not always have a cardiac origin. More than half of the patients consulting the emergency department due to chest pain are diagnosed with non-cardiac chest pain (NCCP) or unexplained chest pain. ${ }^{2,7-12}$ Non-cardiac chest pain is defined as angina-like pain with no evidence of ischemic heart disease (IHD) $)^{2,8}$ and unexplained chest pain as pain that has not been explained by any obvious organic cause..$^{13}$

While there are well established guidelines for diagnosing and treating patients with IHD, ${ }^{14-16}$ an international consensus approach to treat patients with NCCP is lacking. Many NCCP patients have recurrent chest pain after discharge and they are seldom satisfied nor convinced by the 'ruled out' cardiac diagnosis, since they receive no other explanation for the pain. ${ }^{17,18}$ Hence, they perceive their condition as less controllable and have less understanding of their symptoms compared to patients with cardiac disease. ${ }^{19}$ We believe that this can possibly lead to mental distress and worries about suffering from an undetected serious disease, which in turn could result in increased contacts with health-care providers.

Research has shown an association between NCCP and depressive symptoms. ${ }^{20-25}$ However, in patients where there is a relation between NCCP and depressive symptoms, the direction of causality between NCCP and depressive symptoms is far from clear as to whether depressive symptoms are the cause or consequence of the chest pain. Furthermore, the impact of depressive 
symptoms on health-care utilization in patients with NCCP is unknown since research in this area is limited. Psychological distress has shown to be common among patients with more

frequent visits in general practice care. ${ }^{26,27}$ Our hypothesis was that NCCP patients might utilize a substantial amount of health-care resources due to the lack of explanations for the chest pain. However, there is sparse research on the course of illness in patients with NCCP during longterm follow-up after discharge and the amount of health-care they utilize compared to patients with IHD, as summarized by Webster et al. ${ }^{25}$ We therefore set out to compare depressive symptoms and health-care utilization in patients admitted for later proven NCCP compared to patients with IHD presenting with acute myocardial infarction (AMI) and Angina Pectoris (AP) over a one-year follow-up after an acute chest pain event.

\section{Research questions}

(1) What is the prevalence of depressive symptoms in patients admitted for later proven NCCP compared to patients with AMI and AP?

(2) What factors are related to depressive symptoms in patients with NCCP, AMI and AP?

(3) How does the depressive symptom prevalence change the year after an acute chest pain event in patients with NCCP, AMI and AP?

(4) How does health-care utilization differ between patients with NCCP, AMI and AP one year before and one year after an acute chest pain event?

(5) What factors are related to health-care utilization in patients with NCCP, AMI and AP? 
(6) How do depressive symptoms effect health-care utilization in patients with NCCP, AMI and AP?

\section{METHODS}

\section{Study design}

This study had a longitudinal design.

\section{Study participants}

Participants were recruited consecutively among patients discharged from a county hospital in the southeast of Sweden following hospitalization due to acute chest pain between July and December 2008. Patients admitted to the hospital for acute chest pain and discharged diagnosed with NCCP, AP or AMI were eligible for the study. The definition by Eslick ${ }^{8}$ was used which describes NCCP as angina-like pain with no evidence of IHD, since the diagnosis of IHD was ruled out based on health history, status, ECG and cardiac biomarkers. Patients were excluded if they could not complete questionnaires, and/or were living in a nursing home. During the study period 503 patients were eligible for the study and were invited to participate.

\section{Data collection}

Demographic data were collected using a self-administrated questionnaire identifying sociodemographical variables such as age, sex, educational level, work status and income.

Depressive symptoms were collected using a two step procedure. The first step included data collection using 3 screening questions (SQ-3). ${ }^{28,29}$ Patients who answered positively to any of the 
3 questions were considered having depressive symptoms and were therefore instructed to complete the Montgomery Åsberg Depression Rating Scale (MADRS). ${ }^{30}$ Those who did not answer positively to any of the 3 questions did not complete the MADRS. The SQ-3 was used as a screening tool. Only those with depressive symptoms according to SQ-3 continued to complete the MADRS. This procedure is time saving and less burdensome for the patients.

\section{Screening questions (SQ-3)}

Two of the three screening questions are derived from the original Primary care evaluation of Mental Disorders (Prime MD), and were validated by Arroll et al. ${ }^{28,29}$ after the addition of a "help"-question. The Swedish version ${ }^{31}$ was used containing the questions:

1. During the past month have you often been bothered by little interest or pleasure in doing things? ("no" or "yes")

2. During the past month have you often been bothered by feeling down, depressed or hopeless? ("no" or "yes")

3. Is this something with which you would like help? ("no"; "yes, but not today" or "yes")

In previous studies, the SQ-3 showed a $96 \%$ sensitivity and $78-89 \%$ specificity. ${ }^{28,29}$ In our study internal consistency (Kuder Richardson-20) was 0.81. The SQ-3 takes 2-3 minutes to complete. Patients answering yes to at least one of the questions were considered at risk for depressive symptoms and were therefore asked to complete the MADRS to confirm prevalence of depressive symptoms.

\section{Montgomery Åsberg Depression Rating Scale (MADRS)}


The MADRS is a frequently used and easily administered self-rating depression questionnaire that takes about 10 minutes to complete. The Swedish version comprises of 9 items with scores between 0 and 6 , and a score range from 0 to 54 . Higher scores reflect more depressive symptoms. Scores between 12 and 20 imply a moderate depression and scores over 20 imply a severe depression if the condition has lasted for more than two weeks. Scores over 40 indicate a severe depression with high suicidal risk. ${ }^{30,32}$

The MADRS is a valid and reliable unifactorial depression rating scale $\mathrm{e}^{30,33,34}$ and has high internal consistency with Cronbach's alpha values of 0.85-0.92 in patients with major depressive disorder and stroke. ${ }^{35,36}$ In our study the Cronbach's alpha coefficient was 0.86 . In comparison to other measurements the MADRS has the strongest association to the clinician's assessment. ${ }^{33}$

\section{Health-care utilization}

Data on primary care contacts and hospital admissions were collected from the Care Data Warehouse in Östergötland, Sweden. This is a population-based diagnose-related administrative database that contains information about all health-care contacts within primary care, out-patient clinics and hospital care. The database is run by Östergötland County Council. ${ }^{37}$

Data on medical diagnoses one year before study inclusion were also collected from the database. Length of hospital stay was measured in days; each admission lasted for at least one day.

\section{Procedure}

A list of patients discharged with a diagnosis of NCCP, AMI or AP (regardless of previous diagnosis) was given to the researcher every other week between July and December 2008. A 
letter including study information, a written informed consent, the questionnaires and a prestamped envelope was sent to patients who fulfilled the inclusion criteria 1-2 weeks after discharge. One reminder including the questionnaires was sent to those who had not replied within two weeks. Patients indicating that they did not wish to participate were not contacted further.

The one-year follow-up comprised of two parts. During the first part, data were collected using both questionnaires, according to the two-step procedure. The second part consisted of collecting data on health-care utilization from the database. A letter including information about the oneyear follow-up, a written informed consent, the two questionnaires and a pre-stamped envelope was sent to all study participants still alive $(\mathrm{n}=259)$. They were asked to complete the questionnaires within three weeks. A reminder including the questionnaires was sent 3 and 6 weeks after the first mail-out to those who had not replied in time. Patients declining participation were not contacted further.

\section{Statistical analysis}

The Statistical Package for Social Science (SPSS) version 18.0 was used to perform the statistical analysis. Kuder Richardson-20 coefficient of reliability was used to calculate the reliability coefficient for the SQ-3. The socio-demographical variables were described using number and percent. For comparison between groups regarding socio-demographical variables, ANOVA with Bonferroni's post hoc were used for continuous variables and chi square test for categorical variables. Mean value and standard deviation were used to describe prevalence of depressive symptoms. ANOVA and Student's t-test were used to explore differences regarding depressive symptoms between the groups. Multiple linear regression analysis was used to 
explore the relationship between depressive symptoms and socio-demographical variables. For changes in depressive symptom prevalence between baseline and follow-up within groups, paired T-test was used. Kruskal Wallis test and Mann-Whitney U test were used to explore differences regarding changes in depressive symptoms in relation to socio-demographical variables. Non-parametric tests were used, since depressive symptom changes were categorized and socio-demographical variables were on nominal and ordinal level. For differences between groups regarding primary care contacts, ANOVA and Student's t-test were used. For differences within groups between baseline and follow-up, paired T-test was used. To avoid skewness due to differences in number of admissions and length of hospital stay, Kruskal Wallis test and MannWhitney U test with Bonferroni’s correction were used to analyze differences between groups and Wilcoxon signed rank test for differences within groups. Multiple linear regression analysis was used to explore the relationship between depressive symptoms, health-care utilization and socio-demographical variables. Baseline level of depressive symptoms and socio-demographical variables were controlled for in the regression model. Variables were selected based on correlations and were entered into the regression model all at once. Differences were considered significant at $\mathrm{p}<0.05$.

\section{Ethical considerations}

The study was approved by the Regional Ethical Review Board in Linköping (code M12-08 and M12-08 T118-09). Written informed consent was received from all participants. Patients were informed that study participation was voluntary, and that they could withdraw from participation whenever they wished without any consequences. The researchers were not involved in the care of the participants. To ensure patient safety, patients with severe depressive symptoms (MADRS 
score over 20) were contacted by a physician for an evaluation of the need for further examination and treatment.

\section{RESULTS}

\section{Study participants}

Out of the 503 patients approached, 267 (53\%) (131 with NCCP, 66 with AMI and 70 with AP) agreed to participate (figure 1). Participants ranged in age from 21 to 91 years (mean age 67 years) (table 1). Participants were predominantly male (58\%), married (70\%), and retired (61\%). There were no significant differences between the participants and the 236 non-participants regarding sex and age.

Figure 1 about here-

There were significant differences in age, sex and work status between the patients of different diagnose groups (NCCP, AMI, and AP) (table 1). Patients with NCCP were significantly younger than patients with AMI $(\mathrm{p}<0.01)$ and AP $(\mathrm{p}<0.001)$ and more often female $(\mathrm{p}<0.001)$. They also had more patients working, more housewives and students, and fewer retired than expected. AP patients were more often retired than expected. No differences were found regarding marital status, educational level or income between the groups.

Table 1 about here-

At one-year follow-up a total of 200 (75\%) participants agreed to continue study participation, 99 with NCCP, 52 with AMI and 49 with AP (figure 1). Patients who did not want to participate did not differ significantly from those who did regarding any of the socio-demographical variables or depressive symptom prevalence. 


\section{Depressive symptoms}

\section{Prevalence of depressive symptoms at baseline and related factors}

At baseline, 107 (40\%) of the 267 participants answered positively to at least one of the three questions in the SQ-3. These patients then completed the MADRS and $71(66 \%)$ of the 107 patients with a positive SQ-3 showed depressive symptoms according to the MADRS at a cut-off of 12 , representing a total of $27 \%$ of the participants. Of the 71 patients with depressive symptoms, 47 patients had moderate depressive symptoms and 24 patients had severe depressive symptoms. No significant differences were found between patients with NCCP, AMI and AP regarding either prevalence or severity of depressive symptoms. Regression analysis showed that single marital status $(\mathrm{p}<0.05, \mathrm{Beta}=0.20)$ and younger age $(\mathrm{p}<0.01$, Beta $=-0.30)$ were independently related to more depressive symptoms.

\section{Depressive symptoms at one-year follow-up and related factors}

After one year, 86 (43\%) of the participants answered positively to at least one of the questions in the SQ-3. Based on MADRS, 51 of these 86 patients had depressive symptoms at a cut-off of 12 , reflecting that a total of $26 \%$ of the study population reporting depressive symptoms. Of the 51 patients with depressive symptoms 28 patients had moderate depressive symptoms and 23 patients had severe depressive symptoms. Patients with NCCP, AMI and AP did not differ significantly regarding prevalence or severity of depressive symptoms. Having depressive symptoms at baseline was independently related to more depressive symptoms at follow-up $(\mathrm{p}<0.001$, Beta=0.74). No significant association was found between depressive symptoms and the independent socio-demographical variables at the one-year follow-up. 
Regarding the changes between baseline and follow-up, $9 \%$ of the patients with depressive symptoms at baseline had no depressive symptoms at follow-up, 19\% had depressive symptoms both at baseline and follow-up, and $13 \%$ had depressive symptoms at follow-up, but not at baseline (figure 2). Nine percent of patients with depressive symptoms at baseline were lost at follow-up and the prognosis of depressive symptoms for these was unknown. No significant differences were found regarding depressive symptom changes between baseline and follow-up in relation to the socio-demographical variables or diagnosis.

Figure 2 about here

\section{Health-care utilization and related factors}

\section{Contacts with primary care and outpatient departments}

Almost 9500 contacts were reported for primary care and outpatient departments over a two-year period ( 1 year before and 1 year after inclusion), with $60 \%(n=5611)$ registered the year after study inclusion. On average, patients with NCCP, AMI, and AP had 33, 33, and 45 contacts registered respectively (table 2) during the two years of data collection. In all groups the most common type of contact was individual clinic visits followed by telephone contacts. The most common care givers were physicians and primary care nurses.

Table 2 about here

All groups had significantly more contacts the year after inclusion than the year before $(\mathrm{p}<0.05)$. Based on the total number of contacts over the two years, patients with AP contacted health-care providers significantly more than NCCP and AMI patients. This difference was not significant when contacts were divided between the two years. However, patients with AP had more 
contacts than patients with AMI the year before inclusion. Multivariate regression analysis showed that patients with depressive symptoms at baseline had more contacts with health-care providers the year before inclusion $(\mathrm{p}<0.01$, Beta $=0.27$ ), but not the year after (not presented in table). No significant association was found in relation to the other independent variables.

\section{Hospital admissions and length of hospital stay}

\section{Hospital admissions}

In total the study population had 632 hospital admissions during the two year period, divided into 354 hospital admissions the year before inclusion and 278 the year after. Table 3 shows the number of hospital admissions and the differences between the groups 1 year before and 1 year after inclusion. Patients with NCCP, AMI and AP had 1.7, 2.7 and 3.5 admissions per patient respectively during the two year period. Patients with NCCP had significantly fewer hospital admissions than both AMI and AP patients $(\mathrm{p}<0.001)$ the year before inclusion. Also AP patients had significantly fewer hospital admissions than AMI patients $(\mathrm{p}<0.05)$. The year after inclusion, AP patients had more hospital admissions than both NCCP $(\mathrm{p}<0.01)$ and AMI patients $(\mathrm{p}<0.05)$, but no difference was found between NCCP and AMI patients ( $\mathrm{p}=0.474)$. Only AMI patients had significantly more hospital admissions the year before inclusion, 2 per patient, than the year after, 0.7 per patient.

Table 3 about here-

Sixty-six percent of the patients with NCCP did not have any hospital admissions the year before inclusion compared to $17 \%$ and $36 \%$ for patients with AMI and AP. In contrast to the AMI group, a small number of patients $(n=7)$ both in NCCP and AP groups were admitted more 
than all the rest together. The multiple linear regression analysis (table 4) showed no differences regarding number of hospital admissions in relation to the independent variables the year before inclusion except for diagnosis and baseline depressive symptoms. Having depressive symptoms at baseline was also independently related to more hospital admissions the year after inclusion, which also older age was.

Table 4 about here-

Length of hospital stay

On average the NCCP patients were hospitalized 2.3 days the year before inclusion, which was significantly shorter than both AMI and AP patients $(\mathrm{p}<0.001)$, who were hospitalized 5.5 and 5.7 days respectively. The year after inclusion, NCCP patients were hospitalized 3.4 days, which was significantly shorter than AP patients $(\mathrm{p}<0.01)$ who were hospitalized 5.5 days. No significant difference was found between NCCP and AMI patients who were hospitalized 2.3 days. The AMI patients were hospitalized significantly longer pre- than post-inclusion ( $\mathrm{p}=0.001$ ), but the other groups did not differ between the years. On average men were hospitalized 11 days compared to 7 for women, and single persons were hospitalized 12 days compared to 8 for married persons. These findings were significant using bivariate, but not multivariate analysis. Having depressive symptoms at baseline was independently related to longer hospital stay the year before inclusion $(\mathrm{p}<0.05$, Beta $=0.21)$. No relation was found between severity of depressive symptoms and length of hospital stay.

\section{DISCUSSION}


This is the first study that describes health-care utilization in detail in patients with NCCP compared with IHD, and its relation to depressive symptoms. We found that more than $25 \%$ of the total sample had depressive symptoms both at baseline and at follow-up. Other studies have reported prevalence frequencies of depression in $20-50 \%$ of patients with chest pain. ${ }^{7,23,38,39}$ This is a much higher prevalence than in the general population where the depression rate lies between $10-15 \%{ }^{40,41}$ No significant differences were found between patients with NCCP, AMI and AP regarding either prevalence or severity of the depressive symptoms. Previous findings have not been consistent. Robertson and colleagues reported that cardiac patients experience more depressive symptoms than patients with NCCP, although only one week after clinic attendance, ${ }^{19}$ while other researchers found that depressive symptoms were more frequent in patients with medically unexplained symptoms. ${ }^{42}$ Eken and colleagues ${ }^{39}$ reported results in accordance with ours. Since cardiac patients have planned follow-ups with health-care providers where also psychiatric issues can be dealt with, more attention should be paid to patients with NCCP since they often have no planned follow-ups. Another finding was that single and younger persons had more depressive symptoms. These findings correspond with previous research showing that depressive symptoms are common in younger persons, women and persons living alone. $^{43,44}$

Out of the 71 patients with depressive symptoms at baseline, more than half were still experiencing depressive symptoms at follow-up. Spalding and colleagues ${ }^{45}$ reported that many patients were not diagnosed for more than a year, despite chest pain prevalence. This is probably due to the fact that formal screening for depression is not a part of the routine care for patients with chest pain and therefore depression can go unrecognized by cardiovascular physicians and nurses. ${ }^{46}$ At follow-up we also found 26 new patients with depressive symptoms compared to 17 
who had no depressive symptoms any more. One explanation could be that having recurrent and inadequately treated chest pain for a long time, without knowing the cause could lead to worries and depressive symptoms in NCCP and AP patients. ${ }^{45,47}$ Regarding depressive symptoms in AMI patients, also previous research have reported high levels of depression the year after an AMI. ${ }^{48,49}$

Study participants had a high number of contacts with health-care providers during the two year period, which also Leise and colleagues reported. ${ }^{18}$ Although patients with AP had significantly higher number of outpatient contacts than NCCP and AMI patients during the two year period, interestingly there was no difference between patients with NCCP and AMI. Regarding hospital admissions, patients with NCCP had significantly fewer admissions and were hospitalized for significantly shorter periods than both AMI and AP the year before inclusion. The year after inclusion NCCP patients had significantly fewer admissions than AP. The higher use of healthcare in AP could probably be explained by the chronic nature of the condition which differs from the other diagnoses that are more acute. Regarding AMI and NCCP, it is important to reflect on the fact that NCCP patients, who have a much better prognosis, ${ }^{12,50}$ had the same number of contacts during the two years, and also admissions and length of hospital stay the year after inclusion, as those with AMI which is a more serious life-threatening condition. ${ }^{1,10}$ Not all of the patients with NCCP had been admitted prior to inclusion, and only a small part of the patients were frequently readmitted. Mayou and Thompson also stated that a minority of their noncardiac patients were heavy users of hospital resources. ${ }^{10}$ Since many patients had no admissions prior to inclusion, this biases the means and standard deviations presented. Therefore, nonparametric statistics were used to avoid skewness. 
We found that patients with depressive symptoms had increased health-care utilization. Previous studies point out the diversity of the causes for NCCP, including gastro-esophageal reflux disease, chest wall syndromes and psychiatric disease, which may explain the high number of contacts with health-care providers in these patients. ${ }^{5,18}$ All patients had significantly more contacts with primary care the year after inclusion than the year before. It can be expected that the number of contacts was higher after one year since follow-up and rehabilitation were provided during that time. Regarding hospital admissions only patients with AMI had significantly more hospital admissions and were hospitalized longer the year before inclusion than the year after. The number of admissions is most likely due to prodromal unstable angina before infarction..$^{51,52}$ The length of hospital stay might have decreased post-infarction because it became easier to explain the patients' symptoms and provide them with better medical treatment when having a clear diagnosis.

\section{Limitations}

We did not design the study to investigate the cause-effect relationship between chest pain and depressive symptoms. The population mirrors a representative patient group at a large county hospital, but since $47 \%$ of the approached patients did not want to participate the results should be interpreted with caution. Due to there being smaller groups it was not possible to compare the diagnose groups regarding health-care utilization in relation to depressive symptoms. Depressive symptoms are not the same as the diagnosis of depression according to the DSM classification system. Another limitation is that we did not have information on treatment for depression.

\section{Conclusions and clinical implications}


Depressive symptoms are common and persistent among patients with NCCP and do not differ from those with AMI and AP. One out of four had depressive symptoms regardless of diagnosis, and these were persistent in more than half of the patients after one year. Patients with NCCP utilize as much outpatient care as AMI patients, but less hospital care. Patients with depressive symptoms hade more primary care contacts and they were hospitalized more often and longer than those with no depressive symptoms the year before inclusion, independent of diagnosis. Screening and interventions targeting depressive symptoms should be implemented in patient care for NCCP, AMI and AP.

\section{Acknowledgement}

We wish to thank Susanne Spångberg at the Care Data Warehouse in Östergötland for data retrieval. This study was supported by the County Council of Östergötland Sweden, Astrid Andersson Stiftelsen, and the Medical Research of Southeast Sweden (FORSS). 


\section{REFERENCES}

1. Erhardt L, Herlitz J, Bossaert L, et al. Task force on the management of chest pain. Eur Heart J. 2002;23(15):1153-1176.

2. Lenfant C. Chest pain of cardiac and noncardiac origin. Metabolism. 2010;59 Suppl 1:S41-6.

3. Fagring AJ, Lappas G, Kjellgren KI, Welin C, Manhem K, Rosengren A. Twenty-year trends in incidence and 1year mortality in swedish patients hospitalised with non-AMI chest pain. data from 1987-2006 from the swedish hospital and death registries. Heart. 2010;96(13):1043-1049.

4. Nilsson S. Chest pain and ischemic heart disease : Diagnosis and management in primary health care. Vol 1039. Linköping: Department of Medical and Health Sciences, Linköpings universitet; 2008:74. http://urn.kb.se/resolve?urn=urn:nbn:se:liu:diva-11390.

5. Eslick GD, Coulshed DS, Talley NJ. Review article: The burden of illness of non-cardiac chest pain. Aliment Pharmacol Ther. 2002;16(7):1217-1223.

6. The Swedish National Board of Health and Welfare. Statistikdatabasen. Updated 2010 http://www.socialstyrelsen.se/statistik/statistikdatabas.

7. Eslick GD, Jones MP, Talley NJ. Non-cardiac chest pain: Prevalence, risk factors, impact and consulting--a population-based study. Aliment Pharmacol Ther. 2003;17(9):1115-1124.

8. Eslick GD, Talley NJ. Non-cardiac chest pain: Predictors of health care seeking, the types of health care professional consulted, work absenteeism and interruption of daily activities. Aliment Pharmacol Ther. 2004;20(8):909-915.

9. Bass C, Mayou R. Chest pain. BMJ. 2002;325(7364):588-591. 
10. Mayou RA, Thompson DR. Treatment needs of patients admitted for acute chest pain. J Psychosom Res. 2002;53(6):1177-1183.

11. Soares-Filho GL, Freire RC, Biancha K, et al. Use of the hospital anxiety and depression scale (HADS) in a cardiac emergency room: Chest pain unit. Clinics (Sao Paulo). 2009;64(3):209-214.

12. Sekhri N, Feder GS, Junghans C, Hemingway H, Timmis AD. How effective are rapid access chest pain clinics? prognosis of incident angina and non-cardiac chest pain in 8762 consecutive patients. Heart. 2007;93(4):458-463.

13. Jerlock M, Welin C, Rosengren A, Gaston-Johansson F. Pain characteristics in patients with unexplained chest pain and patients with ischemic heart disease. Eur J Cardiovasc Nurs. 2007;6(2):130-136.

14. Van de Werf F, Bax J, Betriu A, et al. Management of acute myocardial infarction in patients presenting with persistent ST-segment elevation: The task force on the management of ST-segment elevation acute myocardial infarction of the european society of cardiology. Eur Heart J. 2008;29(23):2909-2945.

15. Trost JC, Lange RA. Treatment of acute coronary syndrome: Part 1: Non-ST-segment acute coronary syndrome. Crit Care Med. 2011.

16. Association of Physicians of India. API expert consensus document on management of ischemic heart disease. $J$ Assoc Physicians India. 2006;54:469-480.

17. Dumville JC, MacPherson H, Griffith K, Miles JN, Lewin RJ. Non-cardiac chest pain: A retrospective cohort study of patients who attended a rapid access chest pain clinic. Fam Pract. 2007;24(2):152-157.

18. Leise MD, Locke GR,3rd, Dierkhising RA, Zinsmeister AR, Reeder GS, Talley NJ. Patients dismissed from the hospital with a diagnosis of noncardiac chest pain: Cardiac outcomes and health care utilization. Mayo Clin Proc. 2010;85(4):323-330. 
19. Robertson N, Javed N, Samani NJ, Khunti K. Psychological morbidity and illness appraisals of patients with cardiac and non-cardiac chest pain attending a rapid access chest pain clinic: A longitudinal cohort study. Heart. 2008;94(3):e12.

20. Fagring AJ, Kjellgren KI, Rosengren A, Lissner L, Manhem K, Welin C. Depression, anxiety, stress, social interaction and health-related quality of life in men and women with unexplained chest pain. BMC Public Health. 2008;8:165.

21. Demiryoguran NS, Karcioglu O, Topacoglu H, et al. Anxiety disorder in patients with non-specific chest pain in the emergency setting. Emerg Med J. 2006;23(2):99-102.

22. Husser D, Bollmann A, Kuhne C, Molling J, Klein HU. Evaluation of noncardiac chest pain: Diagnostic approach, coping strategies and quality of life. Eur J Pain. 2006;10(1):51-55.

23. Hocaoglu C, Gulec MY, Durmus I. Psychiatric comorbidity in patients with chest pain without a cardiac etiology. Isr J Psychiatry Relat Sci. 2008;45(1):49-54.

24. Jerlock M, Kjellgren KI, Gaston-Johansson F, et al. Psychosocial profile in men and women with unexplained chest pain. J Intern Med. 2008;264(3):265-274.

25. Webster R, Norman P, Goodacre S, Thompson A. The prevalence and correlates of psychological outcomes in patients with acute non-cardiac chest pain: A systematic review. Emerg Med J. 2011.

26. Vedsted P, Christensen MB. Frequent attenders in general practice care: A literature review with special reference to methodological considerations. Public Health. 2005;119(2):118-137.

27. Gili M, Luciano JV, Serrano MJ, Jimenez R, Bauza N, Roca M. Mental disorders among frequent attenders in primary care: A comparison with routine attenders. J Nerv Ment Dis. 2011;199(10):744-749.

28. Arroll B, Khin N, Kerse N. Screening for depression in primary care with two verbally asked questions: Cross sectional study. BMJ. 2003;327(7424):1144-1146. 
29. Arroll B, Goodyear-Smith F, Kerse N, Fishman T, Gunn J. Effect of the addition of a "help" question to two screening questions on specificity for diagnosis of depression in general practice: Diagnostic validity study. $B M J$. 2005;331(7521):884.

30. Montgomery SA, Asberg M. A new depression scale designed to be sensitive to change. Br J Psychiatry. $1979 ; 134: 382-389$

31. Pfizer. Prime MD-läkarens utvärderingshandledning (LUH), uppdaterad för DSM-IV. http://www.pfizer.se/upload/productimages/272/lakarnens_utvarderinghandledning_PrimeMD.pdf.

32. Statens beredning för medicinsk utvärdering. Behandling av depressionssjukdomar. 2004;166:1:540.

33. Mulder RT, Joyce PR, Frampton C. Relationships among measures of treatment outcome in depressed patients. $J$ Affect Disord. 2003;76(1-3):127-135.

34. Muller MJ, Himmerich H, Kienzle B, Szegedi A. Differentiating moderate and severe depression using the montgomery-asberg depression rating scale (MADRS). J Affect Disord. 2003;77(3):255-260.

35. Carmody TJ, Rush AJ, Bernstein I, et al. The montgomery asberg and the hamilton ratings of depression: A comparison of measures. Eur Neuropsychopharmacol. 2006;16(8):601-611.

36. Sagen U, Vik TG, Moum T, Morland T, Finset A, Dammen T. Screening for anxiety and depression after stroke: Comparison of the hospital anxiety and depression scale and the montgomery and asberg depression rating scale. $J$ Psychosom Res. 2009;67(4):325-332.

37. Wirehn AB, Karlsson HM, Carstensen JM. Estimating disease prevalence using a population-based administrative healthcare database. Scand J Public Health. 2007;35(4):424-431.

38. Goodacre S, Mason S, Arnold J, Angelini K. Psychologic morbidity and health-related quality of life of patients assessed in a chest pain observation unit. Ann Emerg Med. 2001;38(4):369-376. 
39. Eken C, Oktay C, Bacanli A, et al. Anxiety and depressive disorders in patients presenting with chest pain to the emergency department: A comparison between cardiac and non-cardiac origin. J Emerg Med. 2010;39(2):144-150.

40. Magnil M, Gunnarsson R, Bjorkelund C. Using patient-centred consultation when screening for depression in elderly patients: A comparative pilot study. Scand J Prim Health Care. 2011;29(1):51-56.

41. Martin-Merino E, Ruigomez A, Johansson S, Wallander MA, Garcia-Rodriguez LA. Study of a cohort of patients newly diagnosed with depression in general practice: Prevalence, incidence, comorbidity, and treatment patterns. Prim Care Companion J Clin Psychiatry. 2010;12(1):PCC.08m00764.

42. Sheps DS, Creed F, Clouse RE. Chest pain in patients with cardiac and noncardiac disease. Psychosom Med. 2004;66(6):861-867.

43. Leifheit-Limson EC, Reid KJ, Kasl SV, et al. The role of social support in health status and depressive symptoms after acute myocardial infarction: Evidence for a stronger relationship among women. Circ Cardiovasc Qual Outcomes. 2010;3(2):143-150.

44. Al-Windi A. Depression in general practice. Nord J Psychiatry. 2005;59(4):272-277.

45. Spalding L, Reay E, Kelly C. Cause and outcome of atypical chest pain in patients admitted to hospital. $J R$ Soc Med. 2003;96(3):122-125.

46. Ziegelstein RC, Kim SY, Kao D, et al. Can doctors and nurses recognize depression in patients hospitalized with an acute myocardial infarction in the absence of formal screening? Psychosom Med. 2005;67(3):393-397.

47. Katz N. The impact of pain management on quality of life. J Pain Symptom Manage. 2002;24(1 Suppl):S38-47.

48. Lane D, Carroll D, Ring C, Beevers DG, Lip GY. The prevalence and persistence of depression and anxiety following myocardial infarction. Br J Health Psychol. 2002;7(Pt 1):11-21.

49. Thombs BD, Bass EB, Ford DE, et al. Prevalence of depression in survivors of acute myocardial infarction. $J$ Gen Intern Med. 2006;21(1):30-38. 
50. Taylor GL, Murphy NF, Berry C, et al. Long-term outcome of low-risk patients attending a rapid-assessment chest pain clinic. Heart. 2008;94(5):628-632.

51. Bahr RD, Leino EV, Christenson RH. Prodromal unstable angina in acute myocardial infarction: Prognostic value of short- and long-term outcome and predictor of infarct size. Am Heart J. 2000;140(1):126-133.

52. Kouvaras G, Bacoulas G. Unstable angina pectoris as a warning symptom before acute myocardial infarction. $Q$ J Med. 1987;64(244):679-684. 


\section{Enrollment}

Approached $(\mathrm{n}=503)$

- Non-cardiac chest pain $(n=230)$

- Myocardial infarction ( $\mathrm{n}=137)$

- Angina pectoris $(\mathrm{n}=136)$

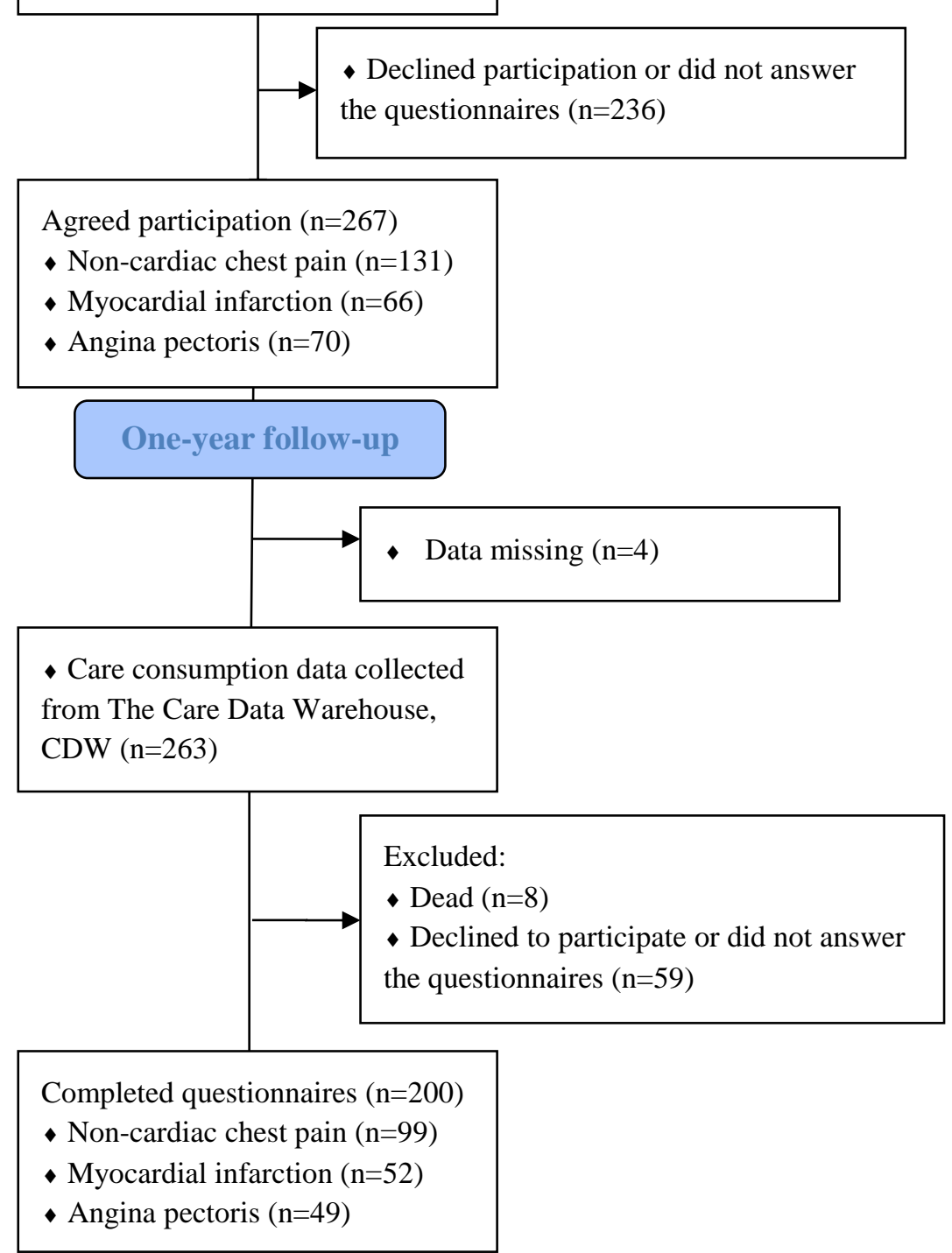

Figure 1: Flow diagram over patient enrollment and data collection at baseline and follow-up 


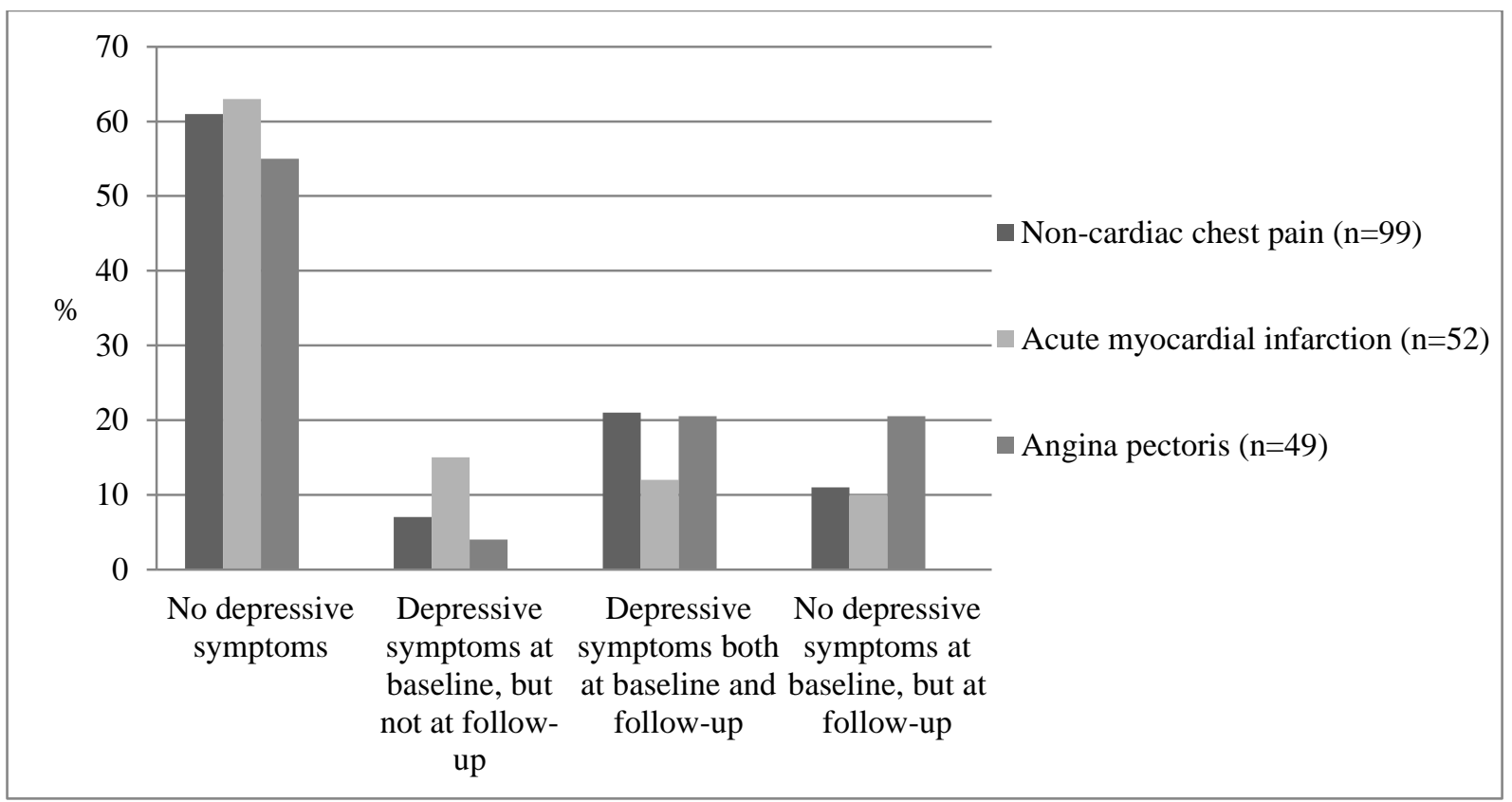

Figure 2: Changes in depressive symptom prevalence between baseline and follow-up, differences between diagnosis groups 
Table 1: Socio-demographic data of the study patients at baseline

\begin{tabular}{|c|c|c|c|c|c|}
\hline & $\begin{array}{c}\text { All } \\
\mathrm{N}=267\end{array}$ & $\begin{array}{l}\text { NCCP } \\
n=131\end{array}$ & $\begin{array}{l}\text { AMI } \\
n=66\end{array}$ & $\begin{array}{c}\text { AP } \\
\mathbf{n}=70\end{array}$ & p-value \\
\hline Age year $($ mean \pm SD $)$ & $67 \pm 14$ & $63 \pm 15$ & $69 \pm 13$ & $72 \pm 12$ & 0.000 \\
\hline Male sex n(\%) & $155(58)$ & $66(50)$ & $44(67)$ & $45(64)$ & 0.043 \\
\hline Married/cohabiting n(\%) & $187(70)$ & $89(68)$ & $52(79)$ & $446(66)$ & 0.191 \\
\hline $\begin{array}{l}\text { Educational level n(\%) } \\
\text { - Compulsory school } \\
\text { - High school } \\
\text { - University }\end{array}$ & $\begin{array}{c}118(44) \\
103(39) \\
46(17)\end{array}$ & $\begin{array}{l}54(41) \\
55(42) \\
22(17)\end{array}$ & $\begin{array}{l}27(41) \\
24(36) \\
15(23)\end{array}$ & $\begin{array}{c}37(53) \\
24(34) \\
9(13)\end{array}$ & 0.358 \\
\hline $\begin{array}{l}\text { Work status n(\%) } \\
\text { - Working } \\
\text { - Retired } \\
\text { - Sick-leave } \\
\text { - Other* }\end{array}$ & $\begin{array}{c}69(26) \\
164(61) \\
21(8) \\
13(5)\end{array}$ & $\begin{array}{l}39(30) \\
68(52) \\
12(9) \\
12(9)\end{array}$ & $\begin{array}{c}14(21) \\
44(67) \\
7(11) \\
1(1)\end{array}$ & $\begin{array}{l}16(23) \\
52(74) \\
2(3) \\
0(0)\end{array}$ & 0.005 \\
\hline $\begin{array}{l}\text { Income n(\%) } \\
\text { - Low } \\
\text { - Middle-range } \\
\text { - High }\end{array}$ & $\begin{array}{c}181(68) \\
54(20) \\
32(12)\end{array}$ & $\begin{array}{l}84(64) \\
29(22) \\
18(14)\end{array}$ & $\begin{array}{c}42(64) \\
15(23) \\
9(13)\end{array}$ & $\begin{array}{c}55(79) \\
10(14) \\
5(7)\end{array}$ & 0.723 \\
\hline $\begin{array}{l}\text { Medical diagnosis } 1 \text { year } \\
\text { pre-admission n(\%) } \\
\text { - NCCP } \\
\text { - AMI } \\
\text { - AP } \\
\text { - Anxiety/depression } \\
\text { - Heart failure } \\
\text { - Diabetes } \\
\text { - Hypertension } \\
\text { - Gastric ulcer } \\
\text { - COPD } \\
\text { - Stroke }\end{array}$ & $\begin{array}{c}37(14) \\
29(11) \\
53(20) \\
10(4) \\
11(4) \\
31(12) \\
1(0) \\
1(0) \\
6(2) \\
2(0)\end{array}$ & $\begin{array}{c}22(17) \\
8(6) \\
13(10) \\
9(7) \\
5(4) \\
9(7) \\
0(0) \\
0(0) \\
2(2) \\
2(2)\end{array}$ & $\begin{array}{c}4(6) \\
15(23) \\
12(18) \\
1(2) \\
0(0) \\
8(12) \\
1(2) \\
1(2) \\
3(5) \\
0(0)\end{array}$ & $\begin{array}{c}11(16) \\
6(9) \\
28(40) \\
0(0) \\
6(9) \\
14(20) \\
0(0) \\
0(0) \\
1(1) \\
0(0)\end{array}$ & \\
\hline
\end{tabular}

$\mathrm{NCCP}=$ non-cardiac chest pain, $\mathrm{AMI}=$ acute myocardial infarction, $\mathrm{AP}=$ angina pectoris, $\mathrm{COPD}=$ chronic obstructive pulmonary disease

* E.g. students and housewives 
Table 2: Number of contacts (mean $\pm \mathrm{SD}$ ) per patient in outpatient clinics and primary care

\begin{tabular}{lccccc}
\hline & $\begin{array}{c}\text { NCCP } \\
\mathbf{n}=\mathbf{1 2 9}\end{array}$ & $\begin{array}{c}\text { AMI } \\
\mathbf{n}=\mathbf{6 5}\end{array}$ & $\begin{array}{c}\text { AP } \\
\mathbf{n}=\mathbf{6 9}\end{array}$ & p-value & F \\
\hline Number of contacts per patient & $15 \pm 16$ & $10 \pm 10$ & $19 \pm 17$ & $\mathrm{p}=0.004^{*}$ & 5.765 \\
$\begin{array}{l}1 \text { year before inclusion (mean } \pm \mathrm{SD}) \\
1 \text { year after inclusion (mean } \pm \text { SD) }\end{array}$ & $18 \pm 26$ & $23 \pm 17$ & $26 \pm 25$ & $\mathrm{p}=0.065^{*}$ & 2.760 \\
Total (mean \pm SD) & $33 \pm 38$ & $33 \pm 22$ & $45 \pm 37$ & $\mathrm{p}<0.038^{*}$ & 3.312 \\
\hline Differences before-after inclusion, $\mathbf{p}$-value & $\mathrm{p}<0.038$ & $\mathrm{P}<0.001$ & $\mathrm{p}=0.005$ & & \\
\hline
\end{tabular}

$\mathrm{NCCP}=$ non-cardiac chest pain, $\mathrm{AMI}=$ acute myocardial infarction, $\mathrm{AP}=$ angina pectoris

= ANOVA 
Table 3: Differences in hospital admissions between the groups 1 year before and 1 year after inclusion. The admission for inclusion not counted

\begin{tabular}{|c|c|c|c|c|}
\hline & $\begin{array}{l}\text { NCCP } \\
n=129\end{array}$ & $\begin{array}{l}\text { AMI } \\
n=65\end{array}$ & $\begin{array}{c}\text { AP } \\
n=69\end{array}$ & p-value \\
\hline $\begin{array}{l}\text { Number of admissions per patient } \\
1 \text { year before inclusion }(\text { mean } \pm \text { SD) } \\
1 \text { year after inclusion }(\text { mean } \pm S D)\end{array}$ & $\begin{array}{l}0.8 \pm 1.5 \\
0.9 \pm 2.1\end{array}$ & $\begin{array}{l}2.0 \pm 1.6 \\
0.7 \pm 1.2\end{array}$ & $\begin{array}{l}1.8 \pm 3.6 \\
1.7 \pm 2.3\end{array}$ & $\begin{array}{c}\mathrm{p}<0.001^{*} \\
\mathrm{p}=0.01^{*}\end{array}$ \\
\hline Total (mean \pm SD) & $1.7 \pm 3.1$ & $2.7 \pm 2.2$ & $3.5 \pm 5.2$ & $\mathrm{p}<0.001^{*}$ \\
\hline Differences before-after inclusion, p-value & $\mathrm{P}=0.435^{\dagger}$ & $\mathrm{P}<0.001^{\dagger}$ & $\mathrm{p}=0.838^{\dagger}$ & \\
\hline
\end{tabular}

$\mathrm{NCCP}=$ non-cardiac chest pain, $\mathrm{AMI}=$ acute myocardial infarction, $\mathrm{AP}=$ angina pectoris

$*$ Kruskal Wallis test

${ }^{\dagger}=$ Wilcoxon signed rank test 
Table 4: Result of multiple linear regression analysis of the relation between hospital admissions and the sociodemographical variables and depressive symptoms

\begin{tabular}{|c|c|c|c|c|c|c|}
\hline \multirow[b]{2}{*}{ Explanatory variables } & \multicolumn{2}{|c|}{$\begin{array}{l}\text { Hospital admissions, } 1 \\
\text { year before inclusion }^{\mathrm{A}}\end{array}$} & \multicolumn{2}{|c|}{$\begin{array}{l}\text { Hospital admissions, } \\
1 \text { year after inclusion }\end{array}$} & \multicolumn{2}{|c|}{$\begin{array}{l}\text { Hospital admissions, } \\
\text { total }^{\mathrm{C}}\end{array}$} \\
\hline & Beta & p-value & Beta & p-value & Beta & p-value \\
\hline Diagnosis & -0.24 & 0.015 & 0.10 & 0.27 & -0.05 & 0.57 \\
\hline Sex & 0.09 & 0.33 & 0.04 & 0.67 & 0.08 & 0.43 \\
\hline Age & 0.13 & 0.28 & 0.29 & 0.015 & 0.25 & 0.03 \\
\hline Marital status & 0.001 & 0.99 & 0.13 & 0.21 & 0.08 & 0.41 \\
\hline Educational level & 0.14 & 0.18 & -0.04 & 0.69 & 0.05 & 0.66 \\
\hline Work status & 0.04 & 0.79 & 0.07 & 0.60 & 0.07 & 0.63 \\
\hline Income & -0.17 & 0.18 & -0.02 & 0.89 & -0.10 & 0.43 \\
\hline Depressive symptoms & 0.26 & 0.012 & 0.21 & 0.039 & 0.27 & 0.008 \\
\hline
\end{tabular}

$\mathrm{A}=\mathrm{R}^{2}=0.17 ; \mathrm{F}=2.42 ; \mathrm{p}$-value $=0.02$

$\mathrm{B}=\mathrm{R}^{2}=0.18 ; \mathrm{F}=2.63 ; \mathrm{p}$-value $=0.012$

$\mathrm{C}=\mathrm{R}^{2}=0.17 ; \mathrm{F}=2.46 ; \mathrm{p}$-value $=0.018$ 